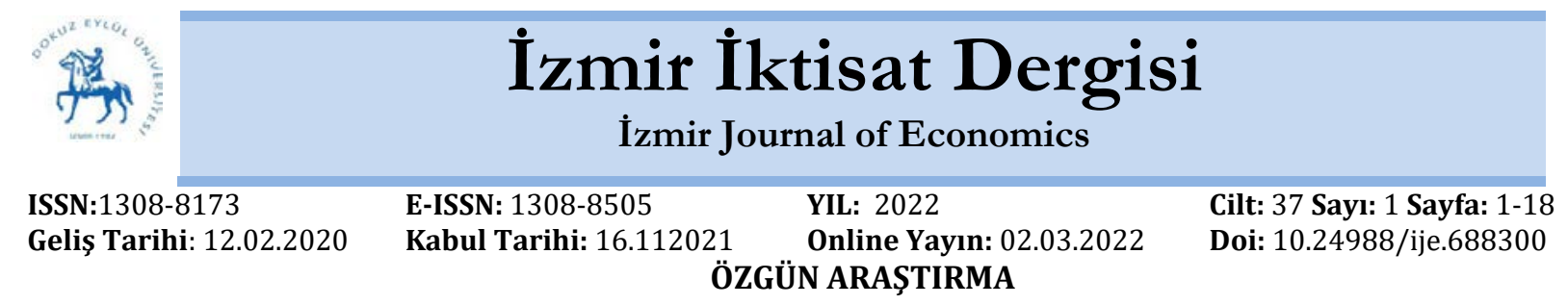

\title{
İş Yerinde Depresif Ruh Hali Ölçeği Geçerlilik ve Güvenirlik Çalışması Kemal EROĞLUER ${ }^{1}$
}

\begin{abstract}
Özet
Bu çalışmada Quinn ve Shepard (1974) tarafından oluşturulan "Depressed Mood at Work" ölçeğinin Türkçeye uyarlanmasl yapılmıştır. Türkçeye "İ̧̧ Yerinde Depresif Ruh Hali" olarak çevrilen ölçeğin geçerlilik ve güvenilirlik çalışması yapılmıştır. Çalışma, ilk aşamada orijinal metnin çevirisi, ikinci aşamasında geçerlilikle ilgili çalışmalar ve son aşamasında ise güvenilirlik ile ilgili analizler olmak üzere üç aşamada yapılmıştır. Ölçeğin Türkçeye uyarlanmasında Brislin (1970) tarafindan önerilen yöntem kullanılmıș, kapsam ve mantıksal geçerliliğinin kontrolünde uzman görüșüne bașvurulmuș ardından yapı geçerliliği (faktör analizi) ile güvenilirliğin kontrolü yapılmıștır. Ankara'da vakıf üniversitelerinde çalıșan 175 öğretim elemanı üzerinde yapılan araștırma sonucu elde edilen veriler analizlerle değerlendirilmiștir. Yapılan analizlerin sonucunda ölçeğin orijinal halinde olduğu gibi tek boyutlu olduğu ve faktör yüklerinin 0,514-0,814 arasında olduğu belirlenmiştir. DFA sonucunda elde edilen uyum iyiliği değerlerinin referans değerler içinde bulunduğu, Cronbach Alpha değerinin 0,918 olduğu, güvenilirlik için gerekli olan diğer istatistiki işlem ve değerlerin daha önce yapılmış çalıșmalar ile uyumlu olduğu belirlenmiștir. Bu kapsamda Quinn ve Shepard (1974) tarafindan geliștirilen "İş Yerinde Depresif Ruh Hali” ölçeğinin tek boyutlu yapısında ve ifadelerinde herhangi bir değişiklik yapılmadan Türkiye’de Sosyal Bilimler alanında yapılacak çalışmalarda güvenilir bir şekilde kullanılabileceği sonucuna ulaşılmıştır.
\end{abstract}

Anahtar kelimeler:Depresif ruh hali, geçerlilik, güvenirlik, ölçek

Jel Kodu: M10, M12, 110

\section{The Validity and Reliability Study of "Depressed Mood at Work" Scale Abstract}

In this study, "Depressed Mood at Work" scale developed by Quinn and Shepard (1974) was adapted to Turkish. The validity and reliability of the scale which is translated to Turkish as "İş Yerinde Depresif Ruh Hali Ölçeği" was conducted. The study was carried out in three stages. Translation of the original scale took place at first, studies conducted on the validity in the second stage, and analyses on the reliability was the last stage. In the adaption of the scale to Turkish, the method proposed by Brislin(1970) was used and regarding the control of the scope and logical validation an expert opinion was received and then eventually reliability was checked with construct validity. The data obtained as a result of the research conducted on 175 lectures who work for Foundation Universities in Ankara. As a result of the study, it was concluded that the scale was one-dimensional and factor loads were between 0,514-0,814. It was found that the goodness of fit values were among the reference values, the Cronbach's Alpha value was 0,918, and the other statistical values reqired for reliability were compatible with previous studies. In this context, it was concluded that the scale "Depressed Mood at Work" developed by Quinn and Shepard (1974) could be used reliably and unchangingly in the researches to be conducted in the field of social sciences in Turkey without any changes in the structure or in the question items of the scale.

Keywords: Depressed mood, validity, reliability, scale

Jel Codes: M10, M12, I10

ATIF ÖNERİsi (APA): Eroğluer, K. (2022). İş Yerinde Depresif Ruh Hali Ölçeği Geçerlilik ve Güvenilirlik Çalışması. İzmir Íktisat Dergisi. 37(1). 1-18. Doi: 10.24988/ije.688300

1 Doç.Dr., Milli Savunma Üniversitesi/Kara Harp Okulu, İşletme ve Yönetim Bilimleri Bölümü, Çankaya / ANKARA, Türkiye EMAIL: k_erogluer@yahoo.com.tr ORCID: 0000-0002-2456-5140 


\section{K. Eroğluer \\ İzmir Íktisat Dergisi / İzmir Journal of Economics \\ Yll/Year: 2022 Cilt/Vol:37 Sayı/No:1 Doi: 10.24988/ije.688300}

\section{GİRİş}

Sanayi devrimi ile birlikte dünya çapında toplumsal yaşam er veya geç, hızlı veya yavaş bir şekilde ama mutlaka değişime uğramış ve uğramaya devam etmektedir. Bu değişim, insan yaşamına pek çok kolaylıklar kazandırması yanında olumsuzlukları da beraberinde getirmiştir. Bu değişim insanoğlu var oldukça onun önlenemez merak ve araştırma isteği nedeniyle sürekli olarak devam edecek, olumlu ve olumsuz sonuçları insanoğluna yeni ufuklar açacaktır.

Depresyon günümüzde yaşanan gelişme ve değişimler nedeniyle insanın günlük yaşamını ve buna paralel olarak iş yaşamını düşünce ve davranış boyutunda olumsuz yönde etkileyen psikiyatrik bir bozukluk olarak kabul edilmektedir. Depresyonun tıbbi anlamda bir hastalıktan ziyade birden fazla alt grupta yer alan hastalıkların birleşimiyle oluştuğu belirtilmiştir (Savrun, 1999: 11).

Depresyon kavramı Latince "depresus" kelimesinden gelmekte ve Türkçede bunalım, çöküntü anlamında (TDK, 2019), tıbbi terminolojide ise "çökkünlük" şeklinde kullanılmaktadır.

Depresyon pek çok faktörden etkilenir. Bu faktörler arasında çoğunlukla, cinsiyet, yaş, medeni durum, sosyoekonomik durum, kişinin sosyal çevresi ve zamana bağlı değişim sayılabilir.

Örgüt yaşamında çalışanların olumsuz duygulara sahip olması, depresyona maruz kalmaları örgütün süreçleri ve işleyişi üzerinde olumsuz yönde etkiler yaratabilecektir. Çalışanların olumsuz duyguları örgüt iklimini, iş barışını, çalışanlar arası ilişkileri, çalışanların örgüte olan bağlılığını, ürün ve hizmet üretimini ve kalitesini, müşterilerle olan ilişkileri yanında dış çevre ile olan ilişkileri de olumsuz yönde etkileyebilmektedir.

Bu çalışma ile Türkçe yazın alanında henüz kullanılmayan İş Yerinde Depresif Ruh Hali (Depressed Mood at Work) ölçeğinin Türkçeye çevrilmesi, geçerlilik ve güvenirlik analizlerinin yapılarak örgütlerde çalışanların "depresif ruh hali"ni belirlemek üzere Türkçe literatüre kazandırılması amaçlanmıştır.

\section{LİTERATÜR}

İnsan ruhu ile ilgili düşünceler ve araştırmalar insanlık tarihi kadar eskidir. Ne olduğu görülmeyen ancak varlığı bilinen ruh, ilkçağ filozoflarından Aristoteles tarafından beden ile birlikte insanı oluşturan iki öğeden biri olduğu, insanda ruhun amaç, bedenin ise araç olduğu ifade edilmiştir (Kaya, 2014: 91).

Örgütlerin en değerli varlıklarından biri olan çalışanlar, insan olmanın kaçınılmaz bir sonucu olarak farklı zamanlarda, farklı şartlarda kimi zaman aynı şartlarda bile farklı duygulara ve duygusal durumlara sahiptirler. Çevresel şartlar kişinin ruh halini etkilediği gibi kimi zamanda kişinin ruh hali olayları ve içinde bulunulan durumları farklı algılamasına neden olmaktadır.

İngilizce literatürde geçen "Mood" kelimesi Türkçede "ruh hali", "haleti ruhiye", "ruhsal durum", "mizaç, hal, keyif, duygu durum" anlamlarında kullanılmaktadır. Türkçede de yaygın olmamakla birlikte son zamanlarda benzer anlamda "Bugün modumda değilim." gibi ifadelerde kullanılmaktadır. Ölçek çalışmasında "mood" kelimesi Türkçe karşılıklarından biri olan "ruh hali" anlamı esas alınarak kullanılmıştır.

Psikoloji alanının önemli bir kavramı olan depresyon ile ilgili pek çok tanımlama yapılmıştır. Budak $(2000,212)$ depresyonu kişinin uzun süre devam eden umutsuzluk hali ve hissi, kendini suçlama, karamsar olma, kendini değersiz hissetme, ilgisizlik, enerjisinin tükenmesi, uyku problemi, yeme bozuklukları ve intihar düşüncesi gibi kişiyi olumsuz yönde etkileyen semptomları gösteren çökkünlük durumu olarak tanımlamıştır (Belge, 2019: 13). 
Depresyon kişilerin kalıtım ile getirdikleri özellikler yanında bazı kişilik özelliklerine göre de ortaya çlkabilir ve etkili olabilir. Kimi zaman hiçbir neden yokken kendisini çökkün hisseden kişinin biyolojik etkenlerden dolayı da depresyon yaşadığı söylenebilir.

Depresyon kavramı sanayileşme süreci ile birlikte insan yaşamını olumsuz etkileyen faktörlerin başında gelmektedir. Hayatın her alanında yaşandığı gibi iş yaşamını da beklenenin aksine olumsuz yönde etkileyen bir faktör olmasına karşın tedavisi mümkün görülmektedir. Tedavi edilmediği takdirde kişilerde hipertansiyon ve diyabet başta olmak üzere pek çok fiziksel rahatsızlığın ve bununla birlikte ruhsal rahatsızlıkların da başlıca nedenlerinden biri olarak görülmektedir.

Depresyonun ne olduğu ile ilgili bir ifadede depresyonun biyolojisi, depresyona yönelik uygulanan tedaviye verdiği tepki, genetik durumu ve prognozu dikkate alındığında karmaşık ve heterojen yapıya sahip psikolojik bir durum olduğu belirtilmiştir (Ören ve Gençdoğan, 2007: 86). Bu anlamda oldukça geniş bir çalışma alanına ve karmaşık bir yapıya sahip olan depresif bozukluklar her kişide farklı etkilere neden olduğu gibi değişik kültürlerde kişiler farklı şekillerde etkilenebilmektedir. Kişilerde depresif bozukluklara neden olan etkenler biyolojik ve psiko-sosyal faktörler olmak üzere iki grupta incelenmiştir. Biyolojik faktörler kapsamında genetik özellikler ile nörotransmitterler sayılmıştır. Psiko-sosyal faktörler kapsamında stres, büyük kayıplar, yoksulluk ve kişilik bozuklukları gibi nedenler sıralanmıştır (Belge, 2019: 16).

Örgütsel açıdan bakıldığında, örgütlerin stres kaynakları arasında kişilerarası ilişkiler, örgütün fiziki koşulları, örgütün izlediği politikalar ve örgütün yapısından kaynaklanan stresler sayılabilir (Luthans, 1992: 404). Örgüt içinde karşılıklı yardımlaşma ve desteğin yerine yıkıcı rekabetin olduğu, kurallara ve ortak değerlere uyum konusunda sorunlar yaşandığı, dedikodunun olduğu, çalışanların ve çalışanlarla üstleri arasında problemlerin yaşanması sonucu bireylerarası ilişkilerden kaynaklanan stresler ortaya çıkar. İş yerindeki zararlı maddeler ve bunların neden olduğu etkiler, ortamın aydınlatılması, sıcaklık durumu çalışan yoğunluğu ve ortamın gürültüsü ise iş yerinin fiziki koşullarının neden olduğu stres kaynakları arasında sayılabilir. Örgüt politikası kapsamında yer alan yetersiz iş tanımları, ücret eşitsizlikleri ve düşük ücret, performans değerlendirmelerinin uygun olmaması stres yaratan diğer etkenlerdir. Örgütsel yapıdan kaynaklanan stres faktörleri arasında merkeziyetçi bir yönetim tarzı, karar alma süreci, ileri derecede uzmanlaşma, iş yükünün sürekli olarak artması, çalışanların terfi ve kendini geliştirme imkânlarının çok az olması ile bürokratik engeller yapıdan kaynaklanan stres unsurlarıdır. Bu stres faktörleri, șiddeti ve sıklığına bağlı olarak çalışanların depresyona girmesine neden olur. Köksal ve Gençdoğan $(2010,163)$ depresyonun "duygu-durum (mood) değișikliği, belirti (semptom), belirtiler toplamı (sendrom) ya da hastalık" olarak çeşitli şekillerde tanımlandığını ve genellikle "ruhsal çöküntü”yü ifade ettiğini (Köknel, 1992) belirtmişlerdir. $\mathrm{Bu}$ dört grup stres faktörü ve bunlardan kaynaklanan depresyon iş yerinde çalışanların işe yabancılaşmalarına, işe devamsızlıklarının artmasına, istenmeyen iş kazalarının meydana gelmesine, çalışanların performanslarının düşmesine, faaliyetlerde etkinlik ve verimliliğin azalmasına ve işgücü devir oranının artmasına neden olabilecektir (Altan, 2018: 138).

Depresyonun çalışanlar üzerinde uzun vadede sağlık yönünden olumsuz etkileri olduğu gibi aynı zamanda onların iş yerlerinde devamsızlıkları ile etkinlik ve verimlilikleri üzerinde de olumsuz etkileri vardır (Gilmor ve Patten, 2007: 19). Bu nedenle kişilerde görülen depresif belirtiler ne seviyede olursa olsun dikkate alınmalı ve gerekli tedavi yapılmalıdır. Zira en düşük etki bile kişi üzerinde durağanlıktan mutsuzluğa kadar pek çok olumsuz duygu durumun yaşanmasına neden olabilecektir. Bu durum "koruyucu ve önleyici ruh sağlığı hizmetleri" bakımından da ön plana çıkmaktadır (Özdel, Bostancı, Özdel ve Oğuzhanoğlu, 2002).

Depresyon insanları genel ve ciddi olarak pek çok yönden etkiler. Düşük mod (ruh hali) bilinen semptomlarına ilave olarak konsantrasyon eksikliği, unutkanlık gibi depresyonun bilişsel semptomları da bu kapsamda değerlendirilir. 
Depresyondan muzdarip olan kişilerin yaşamları boyunca korkutucu ve sorunlu deneyim yaşamış olma olasılıklarının depresyondan muzdarip olmayan diğer kişilere göre daha yüksek olduğu (Brown ve Harris, 1978) ve bu kişilerin çocukluklarında olumsuz olaylar yaşamış olma ihtimallerinin çocukluklarında olumsuz olay yaşamamış kişilere oranla daha yüksek (Brewin, Andrews ve Gotlib, 1993) olduğu belirtilmiştir. Depresif ruh haline sahip kişilerin olumsuz duygusal olayları daha kolay hatırladıkları buna karşın olumlu duygusal olayları daha zor hatırladıkları belirtilmiştir (Sevim, 2017: 9).

\subsection{Literatürde Yer Alan Depresif Ruh Hali Ölçekleri}

Depresyona yönelik yapılan pek çok araștırmada (Beck, Ward, Mendelson, Mock ve Erbaugh, 1961; McGiffin, Galatzer-Levy ve Bonanno, 2019; Zigmond ve Snaith, 1983) depresyonu ortaya çlkaran farklı nedenler belirtilmiş ve buna yönelik yapılan bir araştırmada Wisko ve Nolen-Hoeksema (2009) depresyonun kişinin genetik veya nörobiyolojik yapısındaki bozukluklardan ve genetik faktörlerden meydana geldiğini ifade etmişlerdir (Tuncer ve Dikmen, 2019: 2489).

Depresyonun belirlenmesine yönelik olarak yabancı literatürde yer alan çalışmalardan sınırlı sayıda ölçme çalışmasının (Beck ve Montgomery-Asberg) Türkçeye uyarlandığı belirtilmiştir (Tuncer ve Dikmen, 2019: 2850).

İş yerinde depresif ruh halinin ölçülmesine yönelik yapılan ilk ölçek çalışması Quinn ve Shepard (1974)' a aittir. Yazarlar tarafından geliştirilen depresif ruh hali ölçeği yapılan çeşitli çalışmalarda kullanılmıştır. Aynı ölçek Beehr (1976) tarafından yapılan çalışmada beş farklı örgütte 651 çalışan üzerinde uygulanmış, Spersman-Brown iç güvenirlik katsayısı 0,71 olarak bulunmuştur.

Choi $(2019,150)$ tarafından yapılan iş yerinde dışlanma ve psikolojik sıkıntı arasındaki ilișkiyi belirlemeye yönelik çalışmada depresif ruh hali ölçeği orijinal hali ile kullanılmıştır. Hurrell vd. (1984) polisler üzerinde strese yönelik yaptıkları çalışmada da bu ölçeği kullanmışlardır.

Depresyonun belirlenmesine yönelik kullanılan bir başka ölçek “Beck Depresyon Ölçeği”dir. Bu ölçek kişilerde depresyonun neden olduğu belirtileri ölçmek için Beck ve arkadaşları (1961) tarafından geliştirilmiştir. Beck Depresyon Ölçeği kişinin kendisini değerlendirdiği bir ölçektir. Bu ölçek 21 ifadeden oluşmakta ve Türkçeye uyarlanması 1988 yılında Hisli tarafından yapılmıştır (Yıldız, 2016: 462).

Klein, Lewinsohn, Seeley ve Rohde (2001) yaptıkları çalışmada depresyon üzerinde genetik faktörlerin etkisini incelemişlerdir. Buna göre kişinin birinci derece yakınlarında depresyon görülmüşse, depresyon görülmeyen diğer kişilere nazaran en az iki kat olmak üzere daha fazla depresyona yakalanma olasılığı olduğunu belirtmişlerdir.

Özer ve diğerleri (2001) yaptıkları araştırmada, psikiyatrik değerlendirmeye yönelik yapılan çalışmalarda değişime duyarlı ölçme araçlarının kullanılmasının uygun olacağı belirtmişlerdir. Burns (1996) tarafından geliştirilen "Burns Depresyon Ölçeği" de son zamanlarda yaygın olarak kullanılan güvenilir bir ölçme aracı olarak görülmektedir (Tuncer ve Dikmen, 2019: 2850).

Depresyonun değerlendirilmesine yönelik ölçeklerden diğeri de "Montgomery-Åsberg Depresyon Değerlendirme Ölçeği” (MADÖ Montgomery-Åsberg Depression Rating Scale/MADRS)dir. Bu ölçekte 65 ifade yer almakta ve farklı psikiyatrik belirtileri inceleyen "Comprehensive Psychophatological Rating Scale" (CPRS) isimli ölçekten oluşturulmuştur (Montgomery Asberg, 1979). Ölçek 1979'da Stuart A. Montgomery ve Marie Asberg tarafından oluşturulmuştur. Ölçek oluşturulurken 18-69 yaş arası gibi geniş bir yaş aralığında depresyonu olan hastalar üzerinde değerlendirilmiştir (Özer vd., 2001: 186).

Örgütler içinde bulundukları çevre ile sürekli ilişki içinde olan dinamik yapılardır. Bu dinamizm zamanla yerini atalete bıraktığında, amaçlarından uzaklaştığında, vizyon oluşturamadığında ve 
gelecek tam olarak planlanamadığında örgütlerin de tıpkı insanlar gibi depresyona girmiş olduğu düşünülür. Bu noktadan hareket eden Bilchik $(2000,38) 15$ maddeden oluşan "Örgütünüz İçin Depresyon Kontrol Listesi" ni oluşturmuştur. Sezer $(2011,41)$ bu sorulardan yola çlkarak "Örgütsel Depresyon Ölçeği"ni geliştirmiştir.

Depresyonun değerlendirilmesine yönelik olarak kullanılan bir başka ölçekte "Hamilton Depresyonu Değerlendirme Ölçeği” (HDDÖ)'dir (Snaith, 1993). Hamilton (1960) tarafından geliştirilen ölçekte 17 madde yer almaktadır. Akdemir ve diğerleri (1996) tarafından Türkçe güvenilirliği ve geçerliliği yapılmış olan söz konusu ölçek, 17 maddeli formundan farklı formlarda da kimi zaman kullanılmıştır (Aydemir vd., 2006: 19).

Literatürde yer alan ölçek değerlendirildiğinde genellikle kişilerin depresyon ile ilişkisini belirlemeye yönelik oldukları görülmektedir. Çalışmanın kavramsal kısmında bu alanda önemli olduğu değerlendirilen ölçek çalışmaları kısaca incelenmiştir. Türkçe Literatüre kazandırmak üzere geçerlilik ve güvenilirlik çalışmaları yapılan "İş Yerinde Depresif Ruh Hali Ölçeği” ile kişisel ve örgütsel depresyonun belirlenmesine yönelik geliştirilen ölçeklerle birlikte iş yaşamındaki çalışanların depresif ruh hallerini belirlemeye yönelik önemli bir katkı sağlayacağı değerlendirilmektedir.

\section{3. İ̧ YERINNDE DEPRESIF RUH HALİ ÖLÇEĞíNIN GEÇERLILİK VE GÜVENIRLİK ÇALIŞMASI}

\subsection{Yöntem}

Literatürde konuya katkı sağlayacağı değerlendirilen bu çalışmada "İş Yerinde Depresif Ruh Hali Ölçeği"nin Türkçeye uyarlanması, geçerlilik ve güvenilirlik analizlerinin yapılması ve analizler esnasında yapılan işlemler ile analizler sonucunda elde edilen sonuçlara yönelik bilgiler verilecektir.

\section{2. Çalışmanın Amacı}

Yapılan bu çalışmada Quinn ve Shepard (1974) tarafından 1972 ve 1973 yıllarına yaplan bir çalışmada kullanılan "İş Yerinde Depresif Ruh Hali Ölçeği”nin Türkçeye uyarlanıp, geçerlilik ve güvenilirlik analizleri yapılarak Türkçe literatüre kazandırılması amaçlanmıştır.

\section{3. İş Yerinde Depresif Ruh Hali Ölçeği}

"İş Yerinde Depresif Ruh Hali Ölçeği” Quinn ve Shepard (1974) tarafından geliștirilmiş, tek boyutlu ve on ifadeden oluşan bir ölçektir. İfadeler arasında yer alan dört ifade, "İş yerinde kendimi mutsuz ve keyifsiz hissediyorum", "İş yerinde hiçbir sebep olmaksızın yoruluyorum", "İş yerinde kendimi tedirgin hissediyorum ve sakin olamıyorum" ve "İş yerinde normalde olduğumdan daha asabiyim" ifadeleri olumsuz anlamlı olduklarından analizler yapılırken ters kodlanmıştır. Yapılan tercüme çalışması sonucu elde edilen Türkçe çevirisi ile ölçeğin orijinal hali Ek’te sunulmuştur.

Quinn ve Shepard'ın (1974) çalışmalarında kullandıkları ölçeğin alfa katsayısı 0,77 olarak bulunmuştur. Aynı ölçeği kullanan Beehr (1976) çalışması sonucunda ölçek alfa katsayısını 0,71 olarak bulmuştur. Ölçeğin orijinal halinde ifadeler "1. Sıklıkla”, "2. Bazen”, "3. Nadiren”, "4. Hiçbir zaman" şeklinde 4'lü Likert olarak düzenlenmiştir.

\section{4. Çalışmanın Sınırlılıkları}

Çalışma 2019 yılında Ankara'da bulunan vakıf üniversitelerinde o dönemde görev yapan öğretim elemanları üzerinde yapılmış ve veriler 2019 yılında toplanmıştır. Uygulamanın yapıldığı dönem ve o dönemdeki çalışanlar araştırmanın kısıtlarını oluşturmaktadır. Çalışmanın yalnızca eğitim sektöründe yapılmış olması da ayrı bir kısıttır. Çalışmanın üretim, sağlık, bilişim veya telekomünikasyon gibi farklı sektörde, daha fazla katılımcı ile yapılması farklı sonuçlara ulaşılmasını sağlayabilir. Bu nedenle farklı sektörlerde, farklı zamanlarda ve farklı sayıda çalışana uygulanması gelecekte yapılacak çalışmalarda farklı sonuçların elde edilmesine neden olabilir. Uygulamaya 203 
kişi katılmıştır. Uygulamanın ardından yapılan değerlendirmede 28 anket formunun katılımcılar tarafından eksik veya uygun bir şekilde doldurulmadığı tespit edildiğinden analizlere dâhil edilmemiştir. Analize 175 soru formu dâhil edilmiştir.

\section{5. Çalışmanın Aşamaları}

Çalışma üç aşamada gerçekleştirilmiştir. İlk aşamasında aşağıda ayrıntıları verilen "İş Yerinde Depresif Ruh Hali Ölçeği"nin Türkçe uyarlaması yapılmıştır. Sonraki aşamada ölçeğin geçerlilik çalışmaları kapsamında mantıksal ve kapsam geçerlilikleri ile yapı geçerliliği incelenmiştir. Son aşamada güvenilirliğinin belirlenmesi için ihtiyaç duyulan istatistiksel değerler incelenmiştir.

\subsection{1. İş Yerinde Depresif Ruh Hali Ölçeğinin Türkçeye Uyarlanması}

Orijinal dili İngilizce olan ölçeğin Türkçeye çevrilmesinde Brislin ve diğerleri (1970) tarafından önerilen yöntem izlenmiştir. İfadelerin İngilizceden Türkçeye çevrilmesi Üniversitede görevli dört öğretim görevlisi tarafından yapılmıștır. İlk aşamada öğretim görevlileri birbirlerinden bağımsız olarak çevirileri yapmışlardır. Ardından Türkçe öğretim görevlisi tarafından diğer öğretim görevlilerinin yapmış oldukları çeviriler tek tek incelenerek birleştirilmiştir. Ölçeğin ortaya çıkan Türkçe son hali İngilizce öğretim görevlilerinden oluşan bir ekip tarafından tekrar İngilizceye çevrilmiştir. Çeviri işleminin ardından amacına uygun ölçmeyi sağlayıp sağlamadığını belirlemek amacıyla odak grup çalışması ile bir ön test yapılmıştır.

\subsection{2. İş Yerinde Depresif Ruh Hali Ölçeğinin Geçerliliğinin Kontrolü Amacıyla Yapılan İşlemler}

Farklı bir dilden çeviri yoluyla başka bir dile aktarılacak olan ölçek çalışmalarına yönelik olarak yapılması gereken işlemler arasında ölçeğin geçerliliğinin kontrol edilmesi yer almaktadır. Bu gereklilik sadece çeviri yoluyla yeni ölçek elde etmede değil aynı zamanda yeni ölçek geliştirmede de kullanılır. Ölçeğin geçerliliğini belirlemeye yönelik izlenmesi gereken aşamalardan ilki ölçeğin kapsam, mantıksal ve yapı geçerliğinin kontrol edilmesidir.

Kapsam ve mantıksal geçerliliğin kontrolü genellikle "uzman görüşü" yöntemi ile yapılmaktadır. Bu yöntemde 5-20 arasından konunun uzmanı olan kişilere ihtiyaç duyulmaktadır (Alpar, 2012). Bu çalışmada İş Yerinde Depresif Ruh Hali Ölçeğinin kapsam ve mantıksal geçerliliğinin kontrolü için 15 uzmanın görüşüne başvurulmuştur. Değerlendirmeyi yapacak uzmanlardan ölçekte yer alan 10 ifadenin Türkiye koşullarına göre değerlendirmeleri ve değerlendirmelerini "1. Gerekli”, "2. Gerekli ancak yetersiz" ve "3. Gereksiz" kriterlerine göre yapmaları istenmiştir. Alanında uzman olan akademisyenler tarafından yapılan değerlendirme sonuçları Tablo-1'de sunulmuştur.

Tablo 1: İş Yerinde Depresif Ruh Hali Ölçeğinin İfadelerine İlişkin Uzman Görüşleri

\begin{tabular}{|c|c|c|c|}
\hline İfadeler & Gerekli & $\begin{array}{c}\text { Gerekli, ancak } \\
\text { yetersiz }\end{array}$ & Gerekli değil \\
\hline İSDERUH1 & 15 & - & - \\
\hline İSDERUH2 & 14 & 1 & - \\
\hline İSDERUH3 & 14 & 1 & - \\
\hline İSDERUH4 & 15 & - & - \\
\hline İSDERUH5 & 13 & 2 & - \\
\hline İSDERUH6 & 15 & - & - \\
\hline İSDERUH7 & 15 & - & - \\
\hline ISDERUH8 & 14 & 1 & - \\
\hline İSDERUH9 & 14 & 1 & - \\
\hline ISDERUH10 & 15 & - & - \\
\hline
\end{tabular}


Tablo-1'de sunulan veriler yardımıyla her bir ifadenin kapsam geçerlilik oranı ve tek boyutun kapsam geçerlilik indeksi hesaplanmıştır. Analiz sonucunda İş Yerinde Depresif Ruh Hali Ölçeğinin hesaplanan her bir ifadenin kapsam geçerlilik oranı (KGO) ve orijinal halinde olduğu gibi tek boyutlu haliyle kapsam geçerlilik indeksi değerleri (KGİ) Tablo-2'de verilmiştir.

Tablo 2: İş Yerinde Depresif Ruh Hali Ölçeğinin Kapsam Geçerlilik Oranları ile Kapsam Geçerlilik İndeks Değerleri

\begin{tabular}{|c|c|c|}
\hline İfadeler & Kapsam Geçerlik Oranları (KGO) & $\begin{array}{c}\text { Kapsam Geçerlik İndeksi } \\
\text { (KGi) }\end{array}$ \\
\hline İSDERUH1 & 1 \\
\hline ISDERUH2 & 0,87 \\
\hline İSDERUH3 & 0,87 \\
\hline İSDERUH4 & 1 & \\
\hline ISDERUH5 & 0,73 & \multirow{2}{*}{0,921} \\
\hline İSDERUH6 & 1 & \\
\hline ISDERUH7 & 1 & \\
\hline ISDERUH8 & 0,87 \\
\hline OISSDERUH9 & 0,87 \\
\hline İSDERUH10 & 1 \\
\hline
\end{tabular}

Tablo-2'de sunulan veriler incelendiğinde tüm ifadelerin $\alpha=0,05$ anlamlılık düzeyinde ölçekte yer alması gerektiği görülmektedir (KGO>0,62 ve KGİ>0,67). KGO ve KGİ değerleri ve bu değerlere göre yapılan sınıflandırma Alpar $(2012,414)$ tarafından belirtilmiştir.

\subsubsection{Açıklayıcı Faktör Analizi}

İş Yerinde Depresif Ruh Hali Ölçeğinin yapı geçerliliğini belirlemek amacıyla, açıklayıcı faktör analizinin yapılması literatürde önerilen yöntemler arasında yer almaktadır. Analizde kullanılan veriler 2019 yılında Ankara'da bulunan vakıf üniversitelerinde görevli 203 akademisyene uygulanan anketlerden analize uygun 175 tanesinin incelenmesi ile elde edilmiștir. Akademisyenlerin her bir ifadeye yönelik cevaplarıyla ilgili betimleyici istatistik sonuçları Tablo-3'te verilmiştir.

Tablo 3: İş Yerinde Depresif Ruh Hali Ölçeği Betimleyici İstatistikleri (N=175)

\begin{tabular}{|c|c|c|c|}
\hline İfadeler & Ortalama & Std. Sapma & N \\
\hline ISDERUH1 & 3,57 & 1,01 & 175 \\
\hline ISDERUH2 & 3,55 & 1,04 & 175 \\
\hline ISDERUH3 & 3,76 & 0,93 & 175 \\
\hline ISDERUH4 & 3,12 & 1,01 & 175 \\
\hline ISDERUH5 & 3,82 & 0,79 & 175 \\
\hline ISDERUH6 & 3,20 & 1,12 & 175 \\
\hline ISDERUH7 & 3,60 & 0,77 & 175 \\
\hline ISDERUH8 & 3,54 & 0,98 & 175 \\
\hline ISDERUH9 & 3,44 & 0,97 & 175 \\
\hline İSDERUH10 & 3,82 & 0,90 & \\
\hline
\end{tabular}

Açıklayıcı faktör analizi kapsamında; varsayımların sağlanması, faktörlenme durumunun belirlenmesi, faktör çıkarma yönteminin belirlenmesi, yamaç grafiğinin çizilmesi ve incelenmesi, faktör döndürme yöntemlerinin kullanılması verilerin yorumlanması ve son olarak maddelerin faktör yapılarını düzenleme ve yeniden uygulama adımları uygulanmasının gerekli olduğu belirtilmiştir (Alpar, 2012).

Açıklayıcı ve doğrulayıcı faktör analizinden önce literatürde verilerin çok değişkenli normal dağılım gösterip göstermediğinin kontrol edilmesi önerilmektedir (Alpar, 2012). Bu kapsamda verilerin çok 
değișkenli normal dağılım gösterip göstermediğini belirlemek üzere R programlama dilinde analiz yapılmıştır. Analizlerde read.xl ve MVN paket ve kütüphaneleri kullanılmıştır. Aşağıda verilen analiz sonuçlarına göre verilerin çok değişkenli normal dağılım gösterdiği belirlenmiştir.

Tablo 4: R Programlama Dilinde Yapılan Çok Değişkenli Normal Dağılım Analiz Sonuçları

\begin{tabular}{|c|c|}
\hline R Kodları & $\begin{array}{l}\text { install.packages("readxl") } \\
\text { library(readxl) } \\
\text { install.packages("MVN") } \\
\text { library(MVN) } \\
\text { a=read_excel("C:/Users/kerogluer/Desktop/DRH50.xls", sheet = "Sayfa1") } \\
\text { b=read_excel("C:/Users/kerogluer/Desktop/DRH175.xls", sheet = "Sayfa1") } \\
\text { result <- mvn(data = a, mvnTest = "hz") } \\
\text { result1 <- mvn(data = b, mvnTest = "hz") } \\
\text { result\$multivariateNormality } \\
\text { result1\$multivariateNormality }\end{array}$ \\
\hline $\mathrm{N}=50$ & $\begin{array}{lccc} & \text { Test HZ } & \text { p value } & \text { MVN } \\
1 \text { Henze-Zirkler } & 11.752242 & 0.12^{*} & \text { YES } \\
\end{array}$ \\
\hline $\mathrm{N}=175$ & $\begin{array}{lccc} & \text { Test HZ } & \text { p value } & \text { MVN } \\
\text { 1 Henze-Zirkler } & 9.438051 & 0.09^{*} & \text { YES } \\
\end{array}$ \\
\hline
\end{tabular}

Uygulama sonucu elde edilen verilerin faktörlenebilirliği kontrol edilmiștir. Bu kapsamda literatürde yaygın olarak kullanılan Kaiser-Meyer-Olkin testi ile Bartlett's testi uygulanmıștır. Analiz neticesinde elde edilen veriler Tablo 5'de sunulmuştur.

Tablo 5: KMO ve Bartlett's Testi Sonuçları

\begin{tabular}{|l|l|c|}
\hline \multicolumn{2}{|l|}{ Testler } & İş Yerinde Depresif Ruh Hali Ölçeği (N=175) \\
\hline \multicolumn{2}{|l|}{ Kaiser-Meyer-Olkin (KMO) } & 0,914 \\
\hline \multirow{3}{*}{ Bartlett's Küresellik Testi } & Ki-kare & 849,636 \\
\cline { 2 - 3 } & sd & 45 \\
\cline { 2 - 3 } & $\mathrm{p}$ & 0,000 \\
\hline
\end{tabular}

Tablo-5'te sunulan test değerleri incelendiğinde KMO değerinin çok iyi seviyede (0,90-0,99 çok iyi seviye) ve Bartlett's Küresellik Testi değerinin ise anlamlı olduğu $(\mathrm{p}(0,000)<0,05)$ görülmektedir. KMO değeri, değişkenlerin birbirini yakın tahmin etme gücünün olduğunu; Barlett küresellik testinin sonucu ise değişkenler arasında yeterli seviyede ilişki olduğunu ifade etmektedir (Durmuş vd., 2013). Faktörlerin belirlenmesine yönelik olarak "temel bileșenler analizi" kullanılmıștır. Bu analiz ile açıklayıcı faktör analizine tabi tutulan verilerin kaç faktör altında birleştiği belirlenmektedir. Bu çalışmada "Yamaç Grafiği" kullanılmıştır. Yamaç grafiği verilerin kaç faktör altında toplandığını görsel olarak da göstermesi bakımından tercih edilmiştir. İş Yerinde Depresif Ruh Hali Ölçeği uygulaması sonucu ölçeğin orijinal halinde olduğu gibi faktörlerin tek boyut altında toplandığ görülmüştür. Analiz sonucu ulaşılan yamaç grafiği Şekil 1'de sunulmuştur.

Şekil 1: İş Yerinde Depresif Ruh Hali Ölçeği Yamaç Grafiği

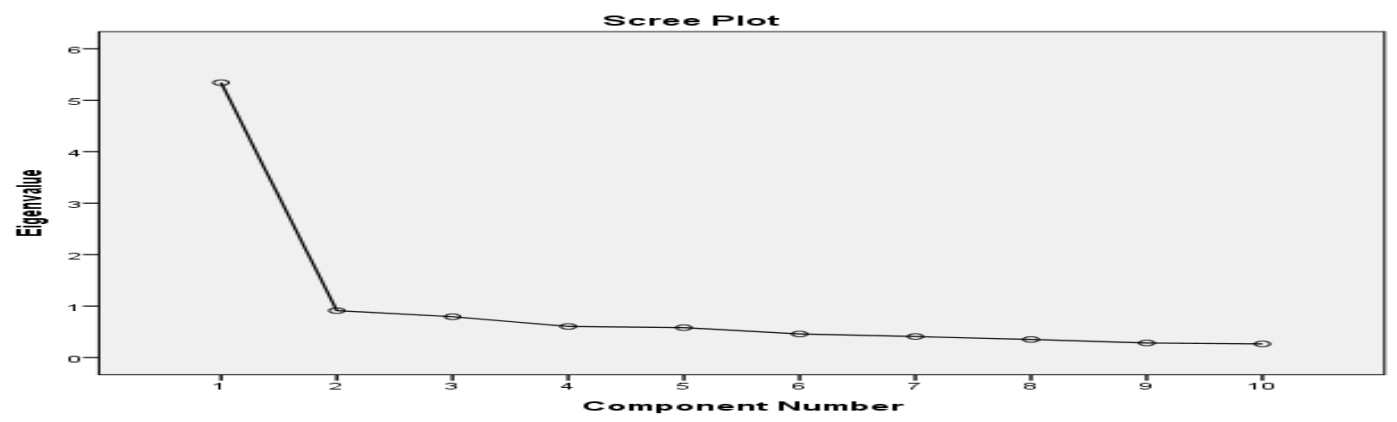


Şekil-1'de sunulan grafik incelendiğinde, İş Yerinde Depresif Ruh Hali Ölçeğine ait verilerin tek boyutta toplanması gerektiği görülmektedir. Bu sonuç, İş Yerinde Depresif Ruh Hali Ölçeğinin orijinal halinde olduğu gibi tek boyut altında toplanması gerektiğini ifade eder. $\mathrm{Bu}$ analizle birlikte elde edilen sonucun diğer analizlerle de desteklenmesi gereklidir.

Yapılan analiz sonucunda elde edilen yamaç grafiğine göre ölçeğin tek boyut altında toplandı̆̆ı görülmüş ve bu boyut altında bulunan tüm ifadelerin faktör yükleri hesaplanmıştır. Ölçeğe ilișkin faktör yükleri Tablo 6'da sunulmuştur.

İş Yerinde Depresif Ruh Hali Ölçeği ifadelerinin kaç boyut altında toplandığı ve ifadelerin faktör yüklerini belirlemek üzere faktör analizi yapılmıştır.

Tablo 6: İfadelerin Faktör Yükleri

\begin{tabular}{|c|c|}
\hline İfadeler & Faktör Yükleri (N=175) \\
\hline ISDERUH1 & 0,811 \\
\hline ISDERUH2 & 0,743 \\
\hline ISDERUH3 & 0,814 \\
\hline ISDERUH4 & 0,741 \\
\hline ISDERUH5 & 0,647 \\
\hline ISDERUH6 & 0,800 \\
\hline ISDERUH7 & 0,514 \\
\hline ISDERUH8 & 0,771 \\
\hline ISDERUH9 & 0,778 \\
\hline ISDERUH10 & 0,633 \\
\hline
\end{tabular}

Analiz sonucunda tüm ifadelerin orijinal ölçekte olduğu gibi tek faktör altında toplandığı görülmüştür. İfadelerin faktör yüklerinin Tablo 6’da belirtildiği gibi 0,514-0,814 aralığında bulunduğu belirlenmiştir. Elde edilen bu değerler faktör yüklerinin iyi seviyede olduğu ve İş Yerinde Depresif Ruh Hali Ölçeğinin ifadelerinin tek boyut altında toplandığını ifade etmektedir. Açıklayıcı faktör analizinde ifadenin bir boyut altında olabilmesi için faktör yükünün 0,3 ve üzerinde olması gerektiği belirtilmiştir (Alpar, 2012). Analiz sonucunda elde edilen faktör yükleri bu şartı sağladığından faktör yüklerinin bu ölçek için uygun olduğu sonucuna ulaşılmıştır.

İş Yerinde Depresif Ruh Hali Ölçeğinde ifadelerinin her birinin toplam varyansın ne kadarını açıkladığına yönelik yapılan analiz ve ulaşılan sonuçlar Tablo-7'de sunulmuştur.

Tablo 7: İş Yerinde Depresif Ruh Hali Ölçeği İçin Açılklanan Toplam Varyans (N=175)

\begin{tabular}{|c|c|c|c|c|c|c|}
\hline \multirow{2}{*}{ Fak. } & \multicolumn{7}{|c|}{ Özdeğerler } & \begin{tabular}{c} 
\% \\
\cline { 2 - 7 }
\end{tabular} & Top. & $\begin{array}{c}\text { \% } \\
\text { Var. }\end{array}$ & $\begin{array}{c}\text { \% } \\
\text { Kümülatif }\end{array}$ & Top. & $\begin{array}{c}\text { Var. } \\
\text { Kümülatif }\end{array}$ \\
\hline 1 & 5,342 & 53,418 & 53,418 & 5,342 & 53,418 & 53,418 \\
\hline 2 & 0,912 & 9,118 & 62,536 & & & \\
\hline 3 & 0,794 & 7,936 & 70,472 & & & \\
\hline 4 & 0,605 & 6,046 & 76,518 & & & \\
\hline 5 & 0,581 & 6,217 & 85,351 & & & \\
\hline 6 & 0,458 & 4,583 & 86,913 & & & \\
\hline 7 & 0,409 & 4,085 & 90,998 & & & \\
\hline 8 & 0,352 & 3,516 & 94,514 & & & \\
\hline 9 & 0,284 & 2,835 & 97,349 & & & \\
\hline 10 & 0,265 & 2,651 & 100,000 & & & \\
\hline
\end{tabular}


Tablo 7'de yer alan değerler incelendiğinde, ölçek ifadelerinin bir boyut altında toplandığı ve bu faktörün toplam varyansın \%53,42 düzeyinde açıkladığı belirlenmiştir. Ulaşılan bu sonucun literatürde yapılan benzer çalışmalar ile karşılaştırıldığında yeterli seviyede olduğu değerlendirilmiștir.

\subsubsection{Doğrulayıcı Faktör Analizi}

İş Yerinde Depresif Ruh Hali Ölçeğinin yapı geçerliliğini kontrol etmek maksadıyla yapılan açıklayıcı faktör analizinin ardından elde edilen verilerin uyumunun değerlendirilmesi amacıyla doğrulayıcı faktör analizi yapılmıştır. Bu analiz ile uyum iyiliği istatistik değerleri hesaplanmıştır. Yapılan doğrulayıcı faktör analizi sonuçları Tablo-8'de ve Şekil-2'de sunulmuştur.

Tablo 8: İş Yerinde Depresif Ruh Hali Ölçeği DFA ve Uyum İyiliği Değerleri

\begin{tabular}{|l|l|l|l|l|l|l|l|}
\hline CMIN & RMR & GFI & AGFI & CMIN/DF & NFI & CFI & RMSEA \\
\hline 59,935 & 0,037 & 0,938 & 0,896 & 1,816 & 0,931 & 0,967 & 0,068 \\
\hline
\end{tabular}

* RMSR: Root Mean Square of Residuals (Hataların Ortalama Karekökü); RMSEA: Root Mean Square Error of Approximation (Yaklaşık Hataların Ortalama Karekökü); TLI: Tucker-Lewis Index (Tucker-Lewis İndeksi); CFI: Comparative Fit Index (Karşılaştırmalı Uyum İndeksi).

Şekil 2: İş Yerinde Depresif Ruh Hali Ölçeği DFA

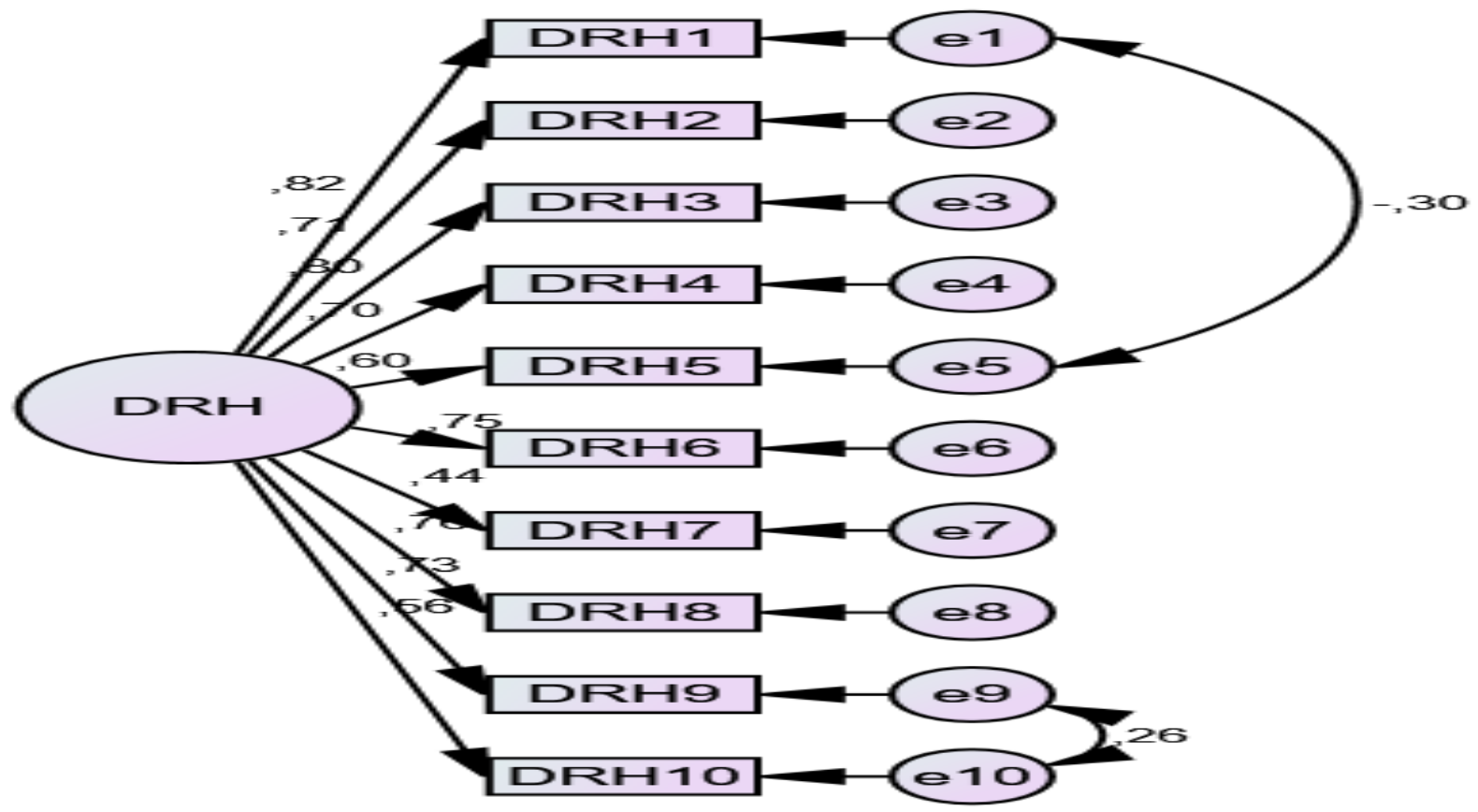

Tablo-8' de doğrulayıcı faktör analizinin sonuçları yer almaktadır. Analiz sonucunda elde edilen uyum iyiliği değerlerinin literatürde belirtilen referans değerleri arasında yer aldığı tespit edilmiştir. Değerlendirmeler Karagöz (2019) tarafından yayınlanan eserinde yer alan uyum iyiliği değerlerine göre yapılmıştır.

\subsection{5. İş Yerinde Depresif Ruh Hali Ölçeğinin Güvenirliğinin Kontrolü}

İş Yerinde Depresif Ruh Hali Ölçeğinin güvenirlik analizi kapsamında literatürde Cronbach's Alpha katsayısı değeri ile ölçek maddelerine ait dört farklı değerin incelenmesi önerilmektedir. Bu kapsamda "madde silindiğinde ölçek ortalaması", "madde silindiğinde ölçek varyansı", "madde silindiğinde Cronbach's alpha katsayısı", "düzeltilmiş madde bütün korelasyon" ve "çoklu korelasyon 
katsayısı" değerlerinin incelenmesi gerekmektedir. Bu maksatla ölçeğin Cronbach's Alpha katsayısı değerleri Tablo-9'da sunulmuştur. Tablo-10'da ölçekte yer alan ifadelere ilişkin "madde silindiğinde ölçek ortalaması", "madde silindiğinde ölçek varyansı", "madde silindiğinde Cronbach's Alpha katsayısı", “düzeltilmiş madde bütün korelasyon" ve "çoklu korelasyon katsayısı" değerleri sunulmuştur.

Tablo 9: Güvenirlik İstatistikleri

\begin{tabular}{|l|l|l|}
\hline Cronbach's Alpha & $\begin{array}{l}\text { Standardize Edilmiş Ifadelerin } \\
\text { Cronbach's Alpha Değeri }\end{array}$ & İade Sayısı \\
\hline 0,918 & 0,918 & 10 \\
\hline
\end{tabular}

Tablo-9'da sunulan Cronbach's Alpha katsayısı incelendiğinde katsayı değerinin oldukça iyi seviyede olduğu belirlenmiştir. Literatürde Tablo-10'da sunulan Cronbach's Alpha katsayısı değerleri ile hesaplanan değerler arasında bir karşılaştırma yapıldığında, ölçeğin oldukça güvenilir değerlerde olduğu sonucuna varılmıştır.

Tablo 10: Cronbach's Alpha Katsayısı Referans Değerleri

\begin{tabular}{|c|l|}
\hline Cronbach's Alpha & \multicolumn{1}{c|}{ Açıklama } \\
\hline $0,80-1,00$ & Geliştirilen test/ölçek yüksek güvenirliğe sahiptir. \\
\hline $0,60-0,79$ & Geliştirilen test/ölçek oldukça güvenilirdir. \\
\hline $0,40-0,59$ & Geliştirilen ölçeğin güvenilirliği oldukça düşüktür. \\
\hline $0,00-0,39$ & Geliştirilen test/ölçek güvenilir değildir. \\
\hline
\end{tabular}

Kaynak: Alpar R. (2012), Uygulamalı İstatistik ve Geçerlilik-Güvenirlik, Detay Yayıncılık, Ankara.

Tablo 11: Diğer Güvenirlik İstatistikleri

\begin{tabular}{|c|c|c|c|c|c|}
\hline & $\begin{array}{c}\text { Madde } \\
\text { Silindiğinde } \\
\text { Ölç. Ort. }\end{array}$ & $\begin{array}{c}\text { Madde } \\
\text { Silindiğinde } \\
\text { Ölç. Var. }\end{array}$ & $\begin{array}{c}\text { Düzeltme } \\
\text { Madde } \\
\text { Bütün } \\
\text { Korelasyon }\end{array}$ & $\begin{array}{c}\text { Çoklu } \\
\text { Korelasyon } \\
\text { Katsayısı }\end{array}$ & $\begin{array}{c}\text { Madde } \\
\text { Silindiğinde } \\
\text { Cronbach's } \\
\text { Alpha } \\
\text { Katsayısı }\end{array}$ \\
\hline İSDERUH1 & 32,000 & 41,434 & 0,807 & 0,686 & 0,903 \\
\hline İSDERUH2 & 31,703 & 41,835 & 0,783 & 0,708 & 0,904 \\
\hline İSDERUH3 & 31,722 & 42,469 & 0,779 & 0,725 & 0,905 \\
\hline İSDERUH4 & 32,222 & 41,572 & 0,773 & 0,687 & 0,905 \\
\hline ISDERUH5 & 31,389 & 46,619 & 0,619 & 0,521 & 0,914 \\
\hline İSDERUH6 & 32,259 & 42,082 & 0,657 & 0,478 & 0,913 \\
\hline ISDERUH7 & 31,629 & 46,124 & 0,599 & 0,413 & 0,915 \\
\hline İSDERUH8 & 31,907 & 43,671 & 0,660 & 0,585 & 0,911 \\
\hline ISDERUH9 & 32,000 & 42,566 & 0,744 & 0,623 & 0,906 \\
\hline ISDERUH10 & 31,667 & 45,132 & 0,541 & 0,539 & 0,918 \\
\hline
\end{tabular}

Ölçeğin güvenirliğinin değerlendirilmesi kapsamında Tablo-11'de sunulan ölçekte yer alan ifadeler ilişkin "madde silindiğinde ölçek ortalaması", "madde silindiğinde ölçek varyansı", "madde silindiğinde Cronbach's alpha katsayısı", "düzeltilmiş madde bütün korelasyon" ve "çoklu korelasyon katsayısı" değerleri incelendiğinde ölçeğin oldukça güvenilir değerlere sahip olduğu belirlenmiştir.

\section{SONUÇ VE ÖNERILLER}

İş Yerinde Depresif Ruh Hali Ölçeği ile ilgili yapılan bu çalışmada Quinn ve Shepard (1974)'ın geliştirdiği ölçeğin Türkçeye uyarlanması, geçerlilik ve güvenilirlik çalışmasının yapılması amaçlanmıştır. Türkçeye uyarlama çalışması belirli aşamalar takip edilerek yapılmıştır. İlk aşamada 
"Depressed Mood at Work" ölçeği İngilizceden Türkçeye çevrilmiştir. Sonraki aşamada ölçeğin geçerliliğine yönelik analizler yapılmıştır. Son aşamada ölçeğin güvenilirliğini belirlemeye yönelik analizler yapılmıştır.

İş Yerinde Depresif Ruh Hali Ölçeği orijinal çalışmada tek boyutlu ve 10 ifadeden oluşmaktadır. Ölçekte yer alan ifadeler alanında uzman kişilerin desteği ile Türkçeye çevrilmiştir. Ölçeğin Türkçe literatürde kullanılabilmesi maksadıyla uzman görüşünden yararlanılarak uygulanabilirliğini belirlemek üzere madde analizleri yapılmıştır. Elde edilen sonuçlara göre ölçeğin boyutunda ve ölçekte yer alan ifadelerde bir değişiklik yapılmadan kullanılabileceği sonucuna ulaşılmıştır.

Ölçeğin yapı geçerliliğini belirlemek amacıyla açıklayıcı ve doğrulayıcı faktör analizleri yapılmıştır. Yapılan açıklayıcı faktör analizine göre ölçek ifadelerinin orijinal halinde olduğu gibi tek boyut altında toplandığı ve ifadelerin faktör yüklerinin 0,514-0,814 arasında değiştiği belirlenmiştir. Ölçekte yer alan ifadelerin toplandığı tek boyutun toplam varyansın \%53,42'sini açılkladığı görülmüştür. Elde edilen sonuç literatürde yapılan çalışmalarla paralellik göstermektedir. Doğrulayıcı faktör analizi neticesinde ulaşılan uyum iyiliği değerlerinden bazıları CMIN 59,935; RMSEA 0,068; CFI 0,967; NFI 0,931; CMIN/DF 1,816; RMR 0,037; GFI 0,938 olarak belirlenmiştir. Elde edilen değerlerin literatürde yer alan referans değerlerine uygun olduğu belirlenmiștir.

Güvenilirlik analizinde Cronbach's Alpha katsayısı ile birlikte Tablo 11'de yer alan "Madde Silindiğinde Ölçek Ortalaması", "Madde Silindiğinde Ölçek Varyansı", "Düzeltilmiş Madde Bütün Korelasyonu", "Çoklu Regresyon Katsayısı" ve "Madde Silindiğinde Cronbach's Alpha Katsayısı" değerleri incelenmiştir. Yapılan analiz sonucunda Cronbach's Alpha katsayısı 0,918 olarak belirlenmiştir. Ölçeğin analizler sonucu elde edilen değerleri göz önüne alındığında ve literatürde yer alan bazı çalışmalarda elde edilen sonuçlarla kıyaslandığında güvenilir bir ölçek olduğu sonucuna ulaşılmıştır.

Çalışma kapsamında yapılan analizlerden elde edilen sonuçların tümü değerlendirildiğinde İş Yerinde Depresif Ruh Hali Ölçeği'nin Türkiye'de Sosyal Bilimler yazın alanında güvenilir bir şekilde kullanılabileceği belirlenmiştir. Yapılacak diğer çalışmalarda ölçek kullanılırken öncelikle doğrulayıcı faktör analizinin yapılması elde edilen sonuçların değerlendirilerek çalışmaya devam edilmesinin uygun olacağı değerlendirilmektedir. 


\section{KAYNAKÇA}

Alpar, R. (2012). Uygulamalı istatistik ve geçerlik güvenirlik, Detay Yayıncılık, Ankara.

Altan, S. (2018). Örgütsel yapıya bağlı stres kaynakları ve örgütsel stresin neden olduğu başlıca sorunlar. Stratejik ve Sosyal Araștırmalar Dergisi, 2(3), 137-158.

Aydemir, Ö., Aytuner D. ve İlkin İ. (2006). Hamilton depresyonu değerlendirme ölçeği yapılandırılmış görüşme kllavuzu mevsimsel duygu durumu bozukluğu versiyonu'nun güvenilirlik ve geçerliliği. Psychiatry in Türkiye, 8(1), 18-21.

Beck, A.T. (1961). An inventory for measuring depression. Arch Gen Psychiatry, 4, 561- 571.

Beck, A. T., Ward, C., Mendelson, M., Mock, J. ve Erbaugh, J. (1961). Beck depression inventory (BDI). Arch Gen Psychiatry, 4(6), 561-571.

Beehr, T. A. (1976). Perceived situational moderators of the relationship between subjective role ambiguity and role strain. Journal of Applied Psychology, 61(1), 35-40.

Belge, J. (2019). Bir grup yetişkinde depresif semptomlar, anksiyete semptomları ve belirsizliğe tahammülsüzlük arasındaki ilișkinin belirlenmesi. Yüksek Lisans Tezi Gelişim Üniversitesi SBE. İstanbul.

Bilchik, G. S. (2000). Organizational depression. H\&HN. Hospitals \& Health Networks, 74(2), 34-38.

Brewin, C.R., Andrews, B. and Gotlib, I.H. (1993). Psychopathology and early experience: A reappraisal of retrospective reports. Psychological Bulletin, 113, 82-98.

Brislin, R.W. (1970). Back-Translation for cross-cultural research, Journal of Cross-Cultural Psychology, 1(3), 185-216.

Brown, G. ve Harris, T. (1978). The social origins of depression. London: Tavistock.

Budak, S. (2000). Psikoloji sözlüğü. Bilim ve Sanat Yayınları. Ankara.

Burns, (1982) Feeling good: The new mood therapy. Signet Boks, New York.

Choi, Y. (2019). The moderating effect of leader member exchange on the relationship between workplace ostracism and psychological distress. Asia-Pacific Journal of Business Administration, 11(2), 146-158.

Durmuş, B. Yurtkoru, E.S. ve Çinko, M. (2013). Sosyal bilimlerde SPSS'le veri analizi (2. Baskı). Beta Yayıncılık, İstanbul.

Gilmour, H. ve Patten, S.B. (2007). Depression at Work. Perspectives on Labour and Income, 8(11), 19-31.

Hamilton, M. (1960). A rating scale for depression. J. Neurol Neurosurg Psychiatr, 23, 56-62.

Hisli, N. (1988). Beck depresyon envanterinin geçerliği üzerine bir çalışma. Psikoloji Dergisi. 4(22), 118-126.

Hurrell, J.J., Pate, A. ve Kliesmet, R. (1984). Stress amog police officers. U.S. department of health and human services. Public Health Service Centers for Disease Control. https://www.ojp.gov/pdffiles1/Digitization/95569NCJRS.pdf

Karagöz, Y. (2019). SPSS AMOS META istatiksel analizler. Nobel Basım Yayıncılık. 2. Baskı. Ankara.

Kaya, M. (2014). Aristoteles'in ruh anlayıșı. Pamukkale Üniversitesi Sosyal Bilimler Enstitüsü Dergisi, 18, 91-98. 
Klein, D. N., Lewinsohn, P. M., Seeley, J. R. annd Rohde, P. (2001). A family study of major depressive disorder in a community sample of adolescents. Archives of General Psychiatry, 58(1), 13-20.

Köknel, Ö. (1992). Depresyon: Ruhsal çöküntü. İstanbul: Altın Kitaplar Yayınevi.

Köksal, F. ve Gençdoğan, B. (2010). Depresif olanlar ile olmayanların suçluluk, utanç ve öfke tarzlarının incelenmesi. Atatürk Üniversitesi Sosyal Bilimler Enstitüsü Dergisi, 9(1), 163-175.

McGiffin, J. N., Galatzer-Levy, I. R. and Bonanno, G. A. (2019). Socioeconomic resources predict trajectories of depression and resilience following disability. Rehabilitation Psychology, 64(1), 98-103.

Luthans, F. (1992). Organizational behavior, McGraw-Hill, New York.

Ören, N. ve Gençdoğan, B. (2007). Lise öğrencilerinin depresyon düzeylerinin bazı değişkenlere göre incelenmesi. Kastamonu Eğitim Dergisi. 15(1), 85-92.

Özdel, L., Bostancı, M., Özdel, O. ve Oğuzhanoğlu, N.K. (2002). Üniversite öğrencilerinde depresif belirtiler ve sosyodemografik özelliklerle ilişkisi. Anadolu Psikiyatri Dergisi, 3, 155-161.

Özer, S. K., Başaran D., Önder T., Elif K. ve Yazıcı M. K. (2001). Montgomery-Åsberg depresyon değerlendirme ölçeği: Değerlendiriciler arası güvenilirlik ve geçerlik çalışması. Türk Psikiyatri Dergisi, 12(3), 185-194.

Quinn, R.P. and Shepard, L.G. (1974). The 1972-1973 quality of employment survey. Institute for Social Research, University of Michigan, Ann Arbor, 90-97.

Savrun M. (1999). Depresyonun tanımı ve epidemiyolojisi. İstanbul Üniversitesi Cerrahpaşa Tıp Fakültesi. Sürekli Tıp Eğitimi Etkinlikleri. İstanbul: 11-17.

Sevim, B. (2017). Depressive mood and memory bias: Is breathing exercise effective? Bahcesehir University, Master's Thesis. Istanbul.

Sezer, S. (2011). Örgüt depresyonu ölçeği'nin geliştirilmesi ve psikometrik niteliklerinin belirlenmesi. "İş, Güç” Endüstri İlişkileri ve İnsan Kaynakları Dergisi, 13(1), 39-50.

TDK, (2021). Türkçe Büyük Sözlük. Sozluk.gov.tr

Tuncer, M. ve Dikmen, M. (2019). Burns depresyon ölçeği Türkçe formunun geçerlilik ve güvenilirlik çalışması. Journal of Social and Humanities Sciences Research, 6(42), 2848-2857.

Wisco, B. E. and Nolen-Hoeksema, S. (2009). The interaction of mood and rumination indepression: effects on mood maintenance and mood-congruent autobiographical memory. Journal of Rational-Emotive and Cognitive Behavior Therapy, 27, 144-159.

Yıldız, M. (2016). Üniversite öğrencilerinde duygusal zekâ yaşam doyumu ve depresyonun cinsiyet ve sınıf seviyelerine göre etkileri. OPUS Dergisi, 6(11), 450-474.

Zigmond, A. S. ve Snaith, R. P. (1983). The hospital anxiety and depression scale. Acta psychiatrica scandinavica, 67(6), 361-370. 


\section{EK: ÖLÇEK FORMU}

\section{1. İşyerinde Depresif Ruh Hali Ölçeği Orijinal Formu.}

\section{DEPRESSED MOOD AT WORK}

1. I feel downhearted and blue. (R)

2. I get tired for no reason. (R)

3. I find myself restless and can't keep still. (R)

4. My mind is as clear as it used to be.

5. I find it easy to do the things I used to do.

6. I feel hopeful about the future.

7. I find it easy to make decisions.

8. I am more irritable than usual. (R)

9. I still enjoy the things I used to.

10. I feel that I am useful and needed.

\section{2. İş Yerinde Depresif Ruh Hali Ölçeği Türkçeye Çevrilmiş Hali}

1. Kendimi üzgün ve kederli hissediyorum. (T)

2. Hiçbir sebep olmaksızın yoruluyorum. (T)

3. Kendimi rahatsız hissediyorum ve sakin olamıyorum. (T)

4. Aklım daha önce olduğu kadar başımda

5. Daha önce yaptığım şeyleri yapmak bana kolay geliyor

6. Gelecekten ümitliyim.

7. Karar vermek bana kolay geliyor.

8. Normalde olduğumdan daha asabiyim. (T)

9. Eskiden zevk aldığım şeylerden hala zevk alıyorum.

10. İhtiyaç duyulan ve gerekli (kişi) olduğumu düşünüyorum. 


\section{EXTENDED ABSTRACT}

\section{The Validity and Reliability Study of "Depressed Mood at Work" Scale}

\section{Introduction}

Economical, technological and social developments have caused the people to be dependent on other people and organizations. These developments designed the organizations as organized organizations. And it's known that a person spends a great amount of his time working in these organizations or to meet his needs. Organizations are a social structures (foundation) where a group of persons consciously create to realise certain purposes. In this structure, people interact with one another in various ways. Since organizations are political areas where power struggles occur, they have influnce on the emotions, thoughts and behaviours of their workers in various ways.

In today's world, these impacts of the organizations might lead to cause the workers to grow negative thoughts to a degree that might even lead depression and therefore affect their lives. In this study, the Turkish adaptation of the scale "Depressed Mood At Work" by Quinn and Sheapard (1974) has been conducted. The validity and reliability of the translation of which "İş Yerinde Depresif Ruh Hali" has been conducted. The validity and reliability study of the scale which was translated into Turkish as "Depressive Mood at Work" was conducted. The study was conducted with the participation of 175 instructors teaching at the foundation universities across Ankara.

\section{Data Set and Method}

The scale "depressed mood at work1" is an unidimentional scale that has consists of ten statements and was developed by Quinn and Shepard (1974). The four statements amidst others are as follows "I feel unhappy at work, I get tired at work for no particular reason, I feel worried at work and can't settle down and finally I'm more nervous than usual at work" and they have been coded reverse for they imply negative meanings.

The study was carried out in three stages. In the first stage was carried out the turkish adaptation of the "depressed mood at work" scale. In the next stage, the logical and content validity and constuct validity of the scale were examined within the scope of validity studies. In the last stage, the stastistical values needed to determine the reliability were examined. In the translation of the scale whose original source language is english, the method that was proposed by Brislin and others (1970) were preferred. The translation of the statements were made by four instructors at a university. Once the translation process was finished a preliminary test with a focus group work (discussion) to determine if the scale was measuring in accordance with its pre-determined purpose was conducted.

Checking of the validity of the content and logical content is usually conduct along with the expert opinion. In this method, five to twenty people who are experts in the subject are needed. In this study, to check the validity of content and logical validity of the scale "depressed mood at work" opinions of fifteen experts have been gathered.

Explanatory Factor Analysis is among the methods recommended in order to determine the construct validity of "depressive mood at work" scale. Within the scope of explanatory factor analysis; it is stated that it is necessary to provide the assumptions, determine the factoring status, determine the factor extraction method, draw and examine the slope graph, use the factor rotation methods, interpret the data, and finally apply the steps of arranging and re-applying the factor structures of the items.

Before the explanatory and confirmatory factor analysis, it is recommended to check whether the data show a multivariate normal distribution in the literature. In this context, analysis was performed in the $\mathrm{R}$ programming language to determine whether the data showed a multivariate normal 
distribution. The read.xl and MVN packages and libraries were used in the analysis. According to the results of the analysis given below, it was determined that the data showed a multivariate normal distribution.

"Principal components analysis" was used to determine the factors. With this analysis, it is determined how many factors the data subjected to explanatory factor analysis are combined under. In this study, "slope graph" was used. The data of the depressive mood at work scale should be collected in one dimension, as in the original scale.

After the explanatory factor analysis to control the construct validity of the depressive mood at work scale, confirmatory factor analysis was performed to evaluate the consistency of the data obtained.

Within the scope of the reliability analysis of the scale of depressive mood at work, it is recommended to examine the Cronbach's Alpha coefficient value and four different values of the scale items in the literature. In this context, "scale mean when item is deleted", "scale variance when item is deleted", "Cronbach's alpha coefficient when item is deleted", "adjusted item whole correlation" and "multiple correlation coefficient" values were analyzed as a result of the analysis.

\section{Empirical Findings}

The translation of the statements / expressions from English to Turkish was done by four lecturers at the university. In the first stage, the lecturers made the translations independently of each other. Then, the translations made by the other lecturers were analyzed one by one by the Turkish lecturer and combined. The final Turkish version of the scale was translated back into English by a team of English lecturers. After the translation process, a pre-test was conducted with a focus group study in order to determine whether it provides the appropriate measurement for its purpose.

In this study, 15 experts were consulted to check the scope and logical validity of the depressive mood at work scale. Almost all of the academicians who are experts in the field that made the evaluation gave their opinion as "necessary" and the content validity index was determined as 0.921.

Before the explanatory and confirmatory factor analysis, an analysis was made to determine whether it showed a normal distribution in the R programming language, and as a result of the analysis, it was determined that the data showed a multivariate normal distribution $(\mathrm{N}=175$, Test HZ 9.438; $\mathrm{p}=0.09)$. As a result of KMO and Bartlett's test, it was determined that the factors were gathered under one dimension, and factor loads and confirmatory factor analysis results were presented in the study. With the "slope graph" made, it was determined that the factors were gathered under one dimension, and the factor loads and confirmatory factor analysis results were presented in the study. Based on the values obtained as a result of the analysis of the reliability of the scale, it was determined that the scale had reliable values.

\section{Discussion and Conclusion}

In this study on the "depressive mood at work scale", it was aimed to adapt the scale developed by Quinn and Shepard (1974) into Turkish, and to conduct validity and reliability studies. The adaptation work into Turkish was carried out by following certain stages. In the first stage, the "depressed mood at work" scale was translated from English to Turkish. In the next step, analyzes for the validity of the scale were made. At the last stage, analyzes were made to determine the reliability of the scale.

In the literature, there are scales to determine different depression created for different purposes. It is evaluated that the scale, whose validity and reliability analyzes were performed in this study, can be used easily in studies to be carried out in business life and can provide important information about depressive mood at work. As a result of the analyzes made, it was concluded that the scale can be used in Turkish literature as in its original form, with one dimension and 10 expressions. 
In the literature, there are scales to determine different depression created for different purposes. It is evaluated that the scale, whose validity and reliability analyzes were performed in this study, can be used easily in studies to be carried out in business life and can provide important information about depressive mood at work. As a result of the analyzes made, it was concluded that the scale can be used in Turkish literature as in its original form, with one dimension and 10 expressions / statements. 